\title{
PENGENALAN ASPEK PASAR PADA SMA TARSISIUS I JAKARTA UNTUK PEMBUATAN PROPOSAL BISNIS
}

\section{Louis Utama ${ }^{1}$, Oey Hannes Widjaja ${ }^{2}$, Richard Andrew ${ }^{3}$, dan Tommy Setiawan Ruslim ${ }^{4}$}

\author{
${ }^{1}$ Program Studi S1 Manajemen, Universitas Tarumanagara Jakarta \\ Email: louisu@fe.untar.ac.id \\ ${ }^{2}$ Program Studi S1 Manajemen, Universitas Tarumanagara Jakarta \\ Email: hannesw@fe.untar.ac.id \\ ${ }^{3}$ Program Studi S1 Manajemen, Universitas Tarumanagara Jakarta \\ Email: richarda@fe.untar.ac.id \\ ${ }^{4}$ Program Studi S1 Manajemen, Universitas Tarumanagara Jakarta \\ Email: tommyr@fe.untar.ac.id
}

\begin{abstract}
Today in a changing world, there are many options High School students can take to fill their spare time outside of the educational process. For example, being a member of the student council. As OSIS member, students have several work programs that must be carried out in accordance with the programs that have been arranged. One program that has great internal and external appeal is the performing arts program. One of the most important things to make a good performing arts activity is making an event proposal. The most basic problem in creating event proposals is a lack of knowledge of the fund sponsor market. If a business proposal can provide a clear market, there will be many people who will be interested in participating in these activities both as contestants and as sponsors of funds. With the implementation of this program in the form of a one-day seminar, it is hoped that some of the participants will be motivated to achieve more and work optimally for internal and external parties with a touch of entrepreneurship. Along with these circumstances, one goal with the thought of the Community Service team (PkM) from Tarumanagara University (Untar) which aims to develop the potential of each student who is educated there to be given training on the importance of market aspects so that students can be easier to determine who is the target market and the target to carry out these activities and the result of this activity is that students can make a good proposal.
\end{abstract}

Keywords: entrepreneurship, market aspects, students

\begin{abstract}
ABSTRAK
Saat ini di dunia yang terus berubah, ada banyak opsi yang dapat dilakukan oleh siswa Sekolah Menengah Atas untuk mengisi waktu luang mereka di luar proses pendidikan. Salah satu hal positif adalah menjadi anggota OSIS. Selama menjadi anggota OSIS, siswa mempunyai beberapa program kerja yang harus dijalankan sesuai dengan yang program yang telah disusun. Salah satu program yang mempunyai daya tarik besar dari internal maupun eksternal adalah program pentas seni. Salah satu hal yang terpenting untuk membuat sebuah kegiatan pentas seni yang baik adalah pembuatan proposal acara. Masalah yang paling dasar dalam pembuatan proposal acara adalah kurangnya pengetahuan mengenai pasar sponsor penyandang dana. Apabila sebuah proposal bisnis dapat memberikan pasar yang jelas maka akan banyak orang yang akan tertarik untuk turut serta dalam kegiatan tersebut baik sebagai peserta lomba maupun sebagai sponsor penyandang dana. Dengan pelaksanaan program ini dalam bentuk seminar sehari diharapkan sebagian dari peserta termotivasi untuk lebih berprestasi dan berkarya secara maksimal kepada pihak internal maupun eksternal sekolah dengan sentuhan kewirausahaan. Seiring dengan keadaan tersebut maka satu tujuan dengan pemikiran dari tim Pengabdian kepada Masyarakat (PKM) yang berasal dari Universitas Tarumanagara (Untar) yang bertujuan untuk mengembangkan potensi dari tiap siswa yang menempuh pendidikan di sana untuk dapat diberikan pelatihan mengenai pentingnya aspek pasar sehingga siswa dapat lebih mudah untuk menentukan siapa pasar sasaran dan target untuk menjalankan kegiatan tersebut dan hasil dari kegiatan ini adalah siswa dapat membuat proposal dengan baik.
\end{abstract}

Kata kunci: kewirausahaan, aspek pasar, siswa

\section{PENDAHULUAN}

Saat ini di dunia yang terus berubah, ada banyak opsi yang dapat dilakukan oleh siswa Sekolah Menengah Atas untuk mengisi waktu luang mereka di luar proses pendidikan. Salah satu hal positif adalah menjadi anggota OSIS. Selama menjadi anggota OSIS, maka siswa mempunyai beberapa program kerja yang harus dijalankan sesuai dengan yang program yang telah disusun. Salah satu program yang mempunyai daya tarik besar dari internal maupun eksternal adalah program pentas seni. 
SMA Tarsisius I yang terletak di Jl. KH. Hasyim Ashari no 26 Jakarta merupakan salah satu sekolah unggulan di Jakarta Pusat. Alumni sekolah tersebut banyak yang merupakan mahasiswa Universitas Tarumanagara. Salah satu kegiatan ekstrakurikuler sekolah adalah kegiatan organisasi yang diwadahi oleh OSIS. Salah satu program unggulan OSIS adalah pembuatan pentas seni sekolah yang bertujuan untuk sarana apresiasi keberhasilan siswa dalam hal ilmu, seni dan olahraga selain untuk sarana pemasaran SMA Tarsisius I.

Salah satu hal yang terpenting untuk membuat sebuah kegiatan pentas seni yang baik adalah pembuatan proposal acara. Masalah yang paling dasar dalam pembuatan proposal acara adalah kurangnya pengetahuan mengenai pasar penyandang dana atau sponsor. Apabila sebuah proposal bisnis dapat memberikan pasar yang jelas maka akan banyak orang yang akan tertarik untuk ikut turut serta dalam kegiatan tersebut baik sebagai peserta lomba maupun sebagai sponsor penyandang dana

Walaupun demikian, untuk menjalankan kegiatan tersebut banyak pihak yang tidak menyadari pentingnya aspek pasar untuk membuat kegiatan tersebut dapat menarik perhatian bagi peserta maupun pihak sponsor yang dapat mendukung kegiatan tersebut. Pengetahuan dasar mengenai aspek pasar dapat membantu untuk menentukan sasaran pasar yang tepat sehingga dapat memberikan kesuksesan pada kegiatan tersebut.

Selain itu tingkat kewirausahaan, performa dan motivasi dari siswa tersebut dapat lebih baik dalam membuat proposal bisnis sehingga merasakan seperti dunia usaha. Untuk itulah tim Pengabdian kepada Masyarakat yang berasal dari Fakultas Ekonomi \& Bisnis Universitas Tarumanagara Jakarta terinspirasi untuk mengadakan pengenalan aspek pasar bagi siswa SMA Tarsisius I Jakarta dalam menjalankan kegiatan program OSIS. Adapun sasaran dari program ini adalah siswa SMA Tarsisius I khususnya anggota OSIS .

Dengan pelaksanaan program ini bertujuan agar peserta termotivasi untuk lebih berprestasi dan berkarya secara maksimal kepada pihak internal maupun eksternal sekolah dalam membuat proposal dengan sentuhan kewirausahaan. Acara pentas seni ini dapat menunjukan bagaimana prestasi siswa secara akademik maupun non akademik yang dapat dipresentasikan kepada pihak internal yaitu orang tua dan guru serta pihak eksternal yaitu calon siswa sekolah, alumni maupun para sponsor acara tersebut. Salah satu hal yang terpenting untuk membuat sebuah kegiatan pentas seni yang baik adalah pembuatan proposal acara.

Apabila sebuah proposal bisnis dapat memberikan pasar yang jelas maka akan banyak orang yang akan tertarik untuk ikut turut serta dalam kegiatan tersebut baik sebagai peserta lomba maupun sebagai sponsor penyandang dana. Seiring dengan keadaan tersebut maka satu tujuan dengan pemikiran dari tim Pengabdian kepada Masyarakat $(\mathrm{PkM})$ yang berasal dari Universitas Tarumanagara (Untar) yang bertujuan untuk mengembangkan potensi dari setiap siswa - siswi yang menempuh pendidikan di sana untuk dapat diberikan pelatihan mengenai pentingnya aspek pasar sehingga siswa dapat lebih mudah untuk menentukan siapa pasar sasaran dan target untuk menjalankan kegiatan tersebut. Dengan diketahuinya aspek pasar sejak awal maka dapat diperoleh lebih banyak peserta maupun para penyandang dana agar tercapai kegiatan yang baik dan memenuhi harapan semua pihak sesuai dengan semangat kewirausahaan (Sobana, 2018).

Untuk dapat mengetahui pasar, maka harus diketahui terlebih dahulu mengenai pasar. Menurut Kotler dan Armstrong (2016) pasar adalah sekelompok pelanggan potensial dengan kebutuhankebutuhan yang serupa yang mau menukarkan sesuatu yang berharga dengan para penjual yang menawarkan berbagai barang atau jasa yaitu cara-cara untuk memenuhi kebutuhan tersebut. Untuk 
itulah Untar, dalam hal ini diwakili oleh Tim PkM Fakultas Ekonomi \& Bisnis turut serta memberikan pendampingan dan penyuluhan terhadap program anggota OSIS dalam pembuatan proposal bisnis dari sekolah.

Hal ini sesuai dengan nilai yang ditanamkan oleh Untar yakni integritas, profesionalitas dan entrepreneurial serta motto yang dibuat oleh Fakultas Ekonomi \& Bisnis (FEB) yakni sebagai kampusnya wirausaha dan profesional. Apalagi jika ditarik lebih jauh ternyata banyak dari alumni SMA Tarsisius I Jakarta yang menjadi mahasiswa di Untar khususnya Fakultas Ekonomi dan Bisnis karena juga didukung oleh lingkungan keluarga sebagai pebisnis handal. Pernyataan ini didukung oleh penelitian yang dilakukan oleh Ayuni (2015) terkait keadaan ekonomi dan dukungan keluarga terhadap siswa. Dengan mampu membuat proposal bisnis dengan baik pada usia remaja maka akan dapat membantu siswa untuk mengembangkan semangat wirausaha untuk menjalankan bisnis

Untuk itulah tim PkM FEB Untar mengembangkan modul untuk membantu siswa mengenali aspek pasar sehingga dapat lebih baik dalam membuat sebuah proposal bisnis selain itu juga menambah minat siswa berwirausaha dalam hal ini mengetahui pasar yang tepat untuk menjalankan kegiatan proposal bisnis dalam sebuah kegiatan pentas seni. Modul ini berisikan, pengenalan terhadap aspek pasar pengenalan terhadap lingkungan bisnis, cara membagi pasar berdasarkan segmentasi. Menurut Cannon et al. (2008) segmentasi pasar merupakan proses dua tahap dari (1) penentuan pasar produk yang luas dan (2) segmentasi pasar produk yang luas ini dalam rangka memilih pasar target dan membangun bauran pemasaran (marketing mix) yang sesuai. Segmentasi pasar adalah pembagian sebuah market menjadi beberapa kelompok pembeli yang berbeda. Tujuan pengelompokan pasar adalah untuk membagi pasar yang berbeda-beda (heterogen) menjadi kelompok-kelompok pasar yang homogen, di mana setiap kelompoknya bisa ditargetkan untuk memasarkan suatu produk sesuai dengan kebutuhan, keinginan, ataupun karakteristik pembeli yang ada di pasar tersebut. Seperti yang disebutkan sebelumnya, tujuan utama pengelompokan pasar adalah untuk membagi pasar yang masih sangat luas menjadi beberapa pasar yang sifatnya homogen. Lebih lengkapnya, berikut adalah beberapa tujuan segmentasi pasar yaitu memudahkan dalam membedakan pasar, pelayanan konsumen menjadi lebih baik, strategi pemasaran lebih terarah, mengenal kompetitor dengan segmen yang sama dan untuk mengevaluasi target dan rencana bisnis Berdasarkan hal tersebut maka tim PkM FEB Untar membuat usulan proposal dengan judul "Pengenalan Aspek Pasar pada SMA TARSISIUS I Jakarta untuk pembuatan proposal bisnis"

\section{METODE PELAKSANAAN PKM}

Pelaksanaan Penyampaian materi dilakukan pada tanggal 2 Maret 2020 mulai pukul 08.00. Acara dimulai oleh Bpk. Subarno selaku kepala sekolah yang akan memberikan kata sambutan. Setelah Kepala Sekolah memberikan kata sambutan, acara seminar pun berlangsung. Materi berisikan serangkaian teori dasar dan pengalaman sebagai narasumber yang merupakan dosen Fakultas Ekonomi dan juga sekaligus sebagai seorang wirausaha.

Setelah pemaparan materi dari empat orang narasumber ini, kegiatan dilanjutkan dengan diskusi dan tanya jawab antara siswa dengan narasumber mengenai permasalahan yang ada dalam diri siswa khususnya dalam pemilihan mitra dalam pembuatan pentas seni. Dalam diskusi dan tanya jawab ini, para siswa akan memperoleh kesempatan untuk bertanya dan secara langsung memeroleh informasi berdasarkan pengalaman narasumber.

Selain itu siswa diharapkan dapat memberikan sharing atas pengalaman yang ada guna menambah pengetahuan bagi narasumber untuk kegiatan tersebut. Sebagai umpan balik dalam kegiatan ini, 
kuesioner akan digunakan untuk mengukur tingkat kepuasan para orang tua siswa selama mengikuti kegiatan seminar ini dan kuesioner untuk mengukur efektivitas pemberian materi melalui seminar ini.

Secara garis besar, anggota tim menjalankan tugas-tugasnya sesuai dengan yang sudah direncanakan, di mana sumberdaya manusia yang terlibat dalam kegiatan ini adalah dosen-dosen yang memiliki kepakaran untuk menyelesaikan persoalan mitra

\section{Gambar 1}

\section{Foto Tanya Jawab Kegiatan PKM}

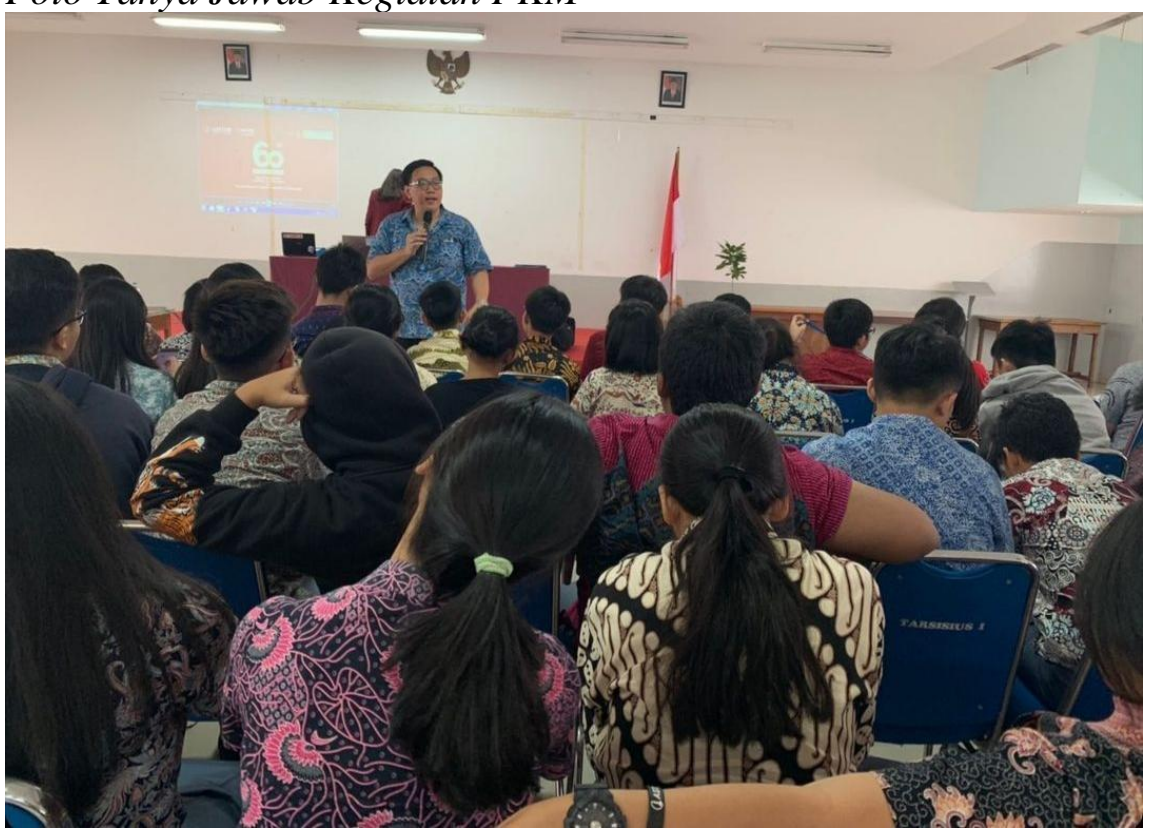

\section{Gambar 2}

\section{Foto Guru dan Peserta PKM}

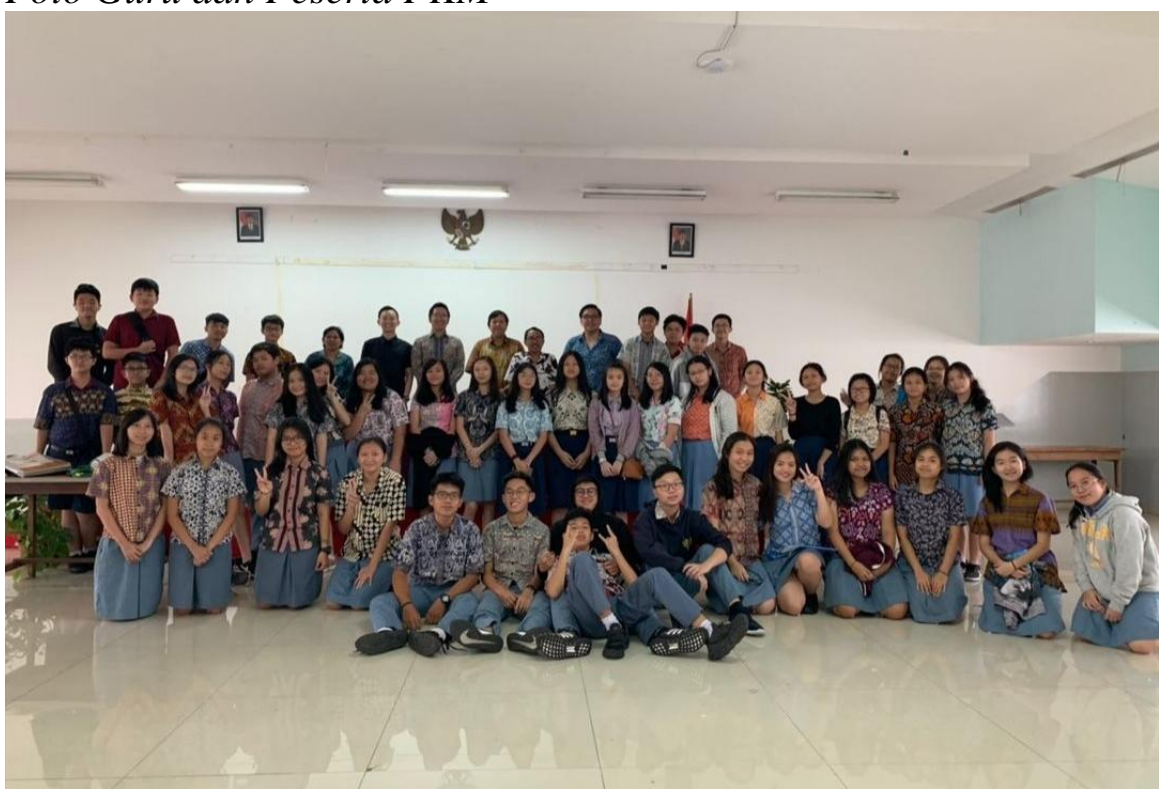




\section{Kelayakan Perguruan Tinggi}

Dalam setiap kegiatan pengabdian masyarakat yang dilakukan oleh dosen dibutuhkan keahlian yang khusus sesuai dengan target dan luaran yang hendak dicapai. Universitas Tarumanagara telah memiliki 8 Fakultas yang mampu mengakomodir kebutuhan keahlian dalam pengabdian di masyarakat. Ke delapan fakultas tersebut adalah: Fakultas Ekonomi, Fakultas Hukum, Fakultas Teknik, Fakultas Kedokteran, Fakultas Seni Rupa dan Desain, Fakultas Psikologi, Fakultas Teknologi Informasi, dan Fakultas Ilmu Komunikasi.

Sumber daya manusia yang terlibat dalam kegiatan ini adalah dosen yang memiliki kepakaran untuk menyelesaikan persoalan mitra. Berikut disajikan dalam Tabel 1 kepakaran masing-masing dosen yang tertuang dalam bentuk kepakaran.

\section{Tabel 1}

Profil Pembicara

\begin{tabular}{cccc}
\hline No. & Nama Tim & Status & Kepakaran \\
\hline 1 & Louis Utama, S.E., M.M. & Dosen & Kewirausahaan \\
\hline 2 & Oey Hannes Widjaja, S.E., M.M., M.I.Kom. & Dosen & SDM \\
\hline 3 & Richard Andrew, S.E., M.M. & Dosen & Pemasaran \\
\hline 4 & Tommy Setiawan Ruslim, S.E., M.M. & Dosen & Operasional \\
\hline
\end{tabular}

\section{HASIL DAN PEMBAHASAN}

Kegiatan pengabdian masyarakat ini dibagi menjadi 4 bagian utama: penyusunan materi, pembuatan proposal, pelaksanaan, dan proses pembuatan pelaporan. Penyusunan materi dilakukan dengan berdiskusi, bertukar pengalaman dan mencari literatur pendukung mengenai dasar tentang kewirausahaan sehingga dapat diwujudkan dalam sebuah materi yang padat dan menarik untuk dijabarkan bagi peserta seminar. Kegiatan pengabdian kepada masyarakat ini ini telah terlaksana dengan baik. Hal ini dapat dilihat dari antusiasme siswa saat melakukan pelatihan ini, peserta menyimak pembahasan teori dengan baik, dan berdiskusi mengenai topik yang diangkat.

Selain dibuat pelatihan dalam pembuatan proposal khususnya untuk menggali aspek pasar, siswa juga secara tidak langsung mendapatkan pelatihan kewirausahaan. Dengan mengetahui pasar yang tepat dalam aspek pasar maka siswa mendapatkan dasar menjadi seorang wirausaha. Untuk dapat menjadi wirausaha yang berhasil perlu mengetahui potensi pasar yang tepat untuk menjalankan usaha. Apabila potensi pasar telah dapat diidentifikasikan maka wirausaha dapat lebih mudah untuk mendapatkan pelanggan sehingga dapat membuat wirausaha semakin sukses dalam menjalankan usahanya.

Materi dapat berguna bagi masyarakat khususnya para siswa untuk membantu memilih mitra dalam pentas seni sekolah khususnya dalam bentuk sponsorship. Dengan adanya pengetahuan aspek pasar maka dapat mempermudah siswa untuk mendapatkan mitra yang sesuai dengan target pasar dari mitra yang sesuai dengan keadaan sekolah. Materi yang diberikan dalam bentuk seminar dan berlangsung dalam tahapan pemberian materi, menjelaskan kepada para peserta seminar, setelah itu dilanjutkan dengan sesi tanya jawab dan sharing mengenai aspek pasar dalam proposal bisnis oleh narasumber.

Program ini berkelanjutan sesuai dengan keadaan permasalahan pada mitra dan permintaan dari pihak mitra untuk mewujudkan para remaja agar kelak menjadi seorang wirausahawan yang dapat mengetahui pasar sehingga dapat menjalankan usaha dengan menjadi wirausaha yang dapat membuka lapangan pekerjaan. 


\section{KESIMPULAN DAN SARAN}

Kegiatan pengabdian kepada masyarakat ini berupa perkenalan aspek pasar dalam pembuatan proposal bisnis dilaksanakan dengan baik dan berjalan sesuai rencana tujuan yang diinginkan. Hal ini dapat dilihat dengan masukan yang di dapat dari kuesioner yang dibagikan selama acara berlangsung. Hasil kuesioner yang diberikan oleh peserta memberikan nilai sangat baik pada topik acara dan manfaat dari acara. Dengan adanya pemberian materi dan berbagi pengalaman di antara para peserta diharapkan pula dapat membentuk beberapa pokok bahasan yang menarik dan lebih rinci yang dapat digunakan oleh para anggota OSIS SMA Tarsisius 1 untuk dapat mengenali aspek pasar sehingga dapat mempermudah dalam memperoleh mitra penyandang dana pada kegiatan pentas seni sekolah. Selain itu juga diharapkan dapat menjadi dasar bagi siswa dengan mengenali pasar yang dituju dapat menambah wawasan dan menambah ide dalam membuat usaha sehingga dapat menjadi wirausaha muda yang sukses. Dengan diadakan acara ini diharapkan dapat memecahkan masalah kurangnya pengetahuan mengenai pasar dalam pencarian penyandang dana atau sponsor dalam kegiatan pentas seni dapat lebih baik dalam pelaksanaan pentas seni yang akan datang.

Selain melatih siswa dalam membuat proposal, kegiatan ini juga mendorong siswa untuk lebih aktif menggali potensi pasar jika menjadi seorang wirausaha. Dengan diketahuinya potensi pasar yang terdapat di dalam aspek pasar maka akan dapat membuat wirausaha menjadi lebih mudah untuk menemukan peluang pasar sehingga akan menjadi wirausaha yang sukses.

Untuk kegiatan berikut, disarankan agar dibuat modul jadi yang lebih baik serta dapat digunakan oleh berbagai pihak, baik untuk bahan ajar maupun untuk kepentingan pemasaran bagi pihak Universitas Tarumanagara dalam memberikan pengajaran mengenai kewirausahaan.

\section{Ucapan Terima kasih (Acknowledgement)}

Kami mengucapkan terima kasih kepada semua pihak yang telah mendukung terlaksananya kegiatan pengabdian kepada masyarakat yang kami lakukan, yaitu: Rektor universitas Tarumanagara, Ketua LPPM Universitas Tarumanagara, Dekan Fakultas Ekonomi Universitas Tarumanagara, Pimpinan SMA TARSISIUS I beserta semua pihak yang tidak dapat kami sebutkan satu persatu yang telah membantu sehingga kegiatan pengabdian kepada masyarakat ini dapat berjalan serta terlaksana dengan baik.

\section{REFERENSI}

Ayuni, A. N. (2015). Kematangan karir siswa kelas xi ditinjau dari tingkat pendidikan orang tua dan keadaan ekonomi keluarga di SMA Negeri 1 Pakem tahun ajaran 2014/2015. Jurnal Riset Mahasiswa Bimbingan dan Konseling.

Cannon, J. P., Perreault, W. D., \& McCarthy, E. J. (2013). Pemasaran dasar: Pendekatan manajerial global:Buku 1. (16th ed.). Salemba Empat.

Sobana, D. H. (2018). Studi kelayakan bisnis (1st ed.). Pustaka Setia.

Kotler, P., \& Amstrong, G. (2016). Prinsip-prinsip pemasaran: Jilid 1 (13th ed.). Erlangga.

Sekolah Tarsisius 1. SMA Tarsisius 1. https://www.tarsisius1.sch.id/sma/ 